\title{
The use of high-resolution MRI to detect thrombosis and lipid-rich carotid artery plaques in a patient with homozygous familial hypercholesterolemia
}

\author{
DZhenjia Wang ${ }^{1,2}$ \\ (iD) Wen Liu', \\ (DD Long Jiang ${ }^{2,3}$ \\ (iD) Luya Wang ${ }^{2}$ \\ (iD) Wei $Y u^{1,2}$
}

\begin{abstract}
1. Department of Radiology, Beijing Anzhen Hospital, Capital Medical University, No. 2 Anzhen Road, Chaoyang District, Beijing 100029, China 2. Beijing Anzhen Hospital, Capital Medical University, Beijing Institute of Heart, Lung, and Blood Vessel Diseases, The Key Laboratory of Remodeling-related Cardiovascular Diseases, No. 2 Anzhen Road, Chaoyang District, Beijing 100029, China 3. Department of Cardiovascular, the Second Affiliated Hospital of Nanchang University, Nanchang 330006, Jiangxi Province, China
\end{abstract}

\section{SUMMARY}

Homozygous familial hypercholesterolemia is a rarely agentic disorder of the lipoprotein metabolism intimately related to premature atherosclerotic cardiovascular disease that can lead to high disability and mortality. Homozygous familial hypercholesterolemia typically affects not only the aortic root, compromising the coronary ostia, but also affects other territories such as the carotid, descending aorta, and renal arteries. Multi-contrast high-resolution magnetic resonance imaging (MRI) provides a validated and useful method to characterize carotid artery atherosclerotic plaques quantitatively. However, very few studies have been done on assessing plaque composition in patients with Homozygous familial hypercholesterolemia using high-resolution MRI. This report is to evaluate the value of MRI in accessing carotid artery disease in patients with Homozygous familial hypercholesterolemia. We describe a 28-year-old patient from Beijing, China, who presented to the Neurology Clinic with intermittent blurred vision of the right eye, headache, nausea, and vomiting for eight years without obvious causes. Familial hypercholesterolemia was suspected based on medical history and laboratory examination. Carotid Doppler ultrasound showed bilateral common carotid artery, internal carotid artery, and external carotid artery wall thickening with hyperechoic signals. Subsequently, high-resolution multi-contrast MRI of the carotid showed calcification with hypo-intense areas located at the middle layer of the plaque, with moderate stenosis. The plaque located at the right bifurcation of the common carotid artery extended to the internal carotid artery, causing lumen stenosis close to occlusion. The patient was treated with right carotid artery endarterectomy. At a 6-month follow-up, there had been no recurrence of the patient's symptoms.

KEYWORDS: Magnetic Resonance Spectroscopy. Plaque, Atherosclerotic. Carotid Intima-Media Thickness. Carotid Arteries. Hyperlipoproteinemia Type II.

\section{INTRODUCTION}

Homozygous familial hypercholesterolemia (HoFH) characterized clinically by plasma cholesterol levels $>13 \mathrm{mmol} / \mathrm{L}$, extensive xanthomas, and followed by markedly premature and progressive atherosclerotic cardiovascular disease (ACVD) is a rare and life-threatening disease' ${ }^{1}$. ACVD typically affects the aortic root, compromising the coronary ostia, but also other territories such as the carotid, descending aorta, and

DATE OF SUBMISSION: 01-May-2019

DATE OF ACCEPTANCE: 30-Jun-2019

CORRESPONDING AUTHOR: Wei Yu

Department of Radiology, Beijing Anzhen Hospital, Capital Medical University, No. 2 Anzhen Road

Beijing 100029 - China - Tel: +86-13552848290

E-mail: yuweimd@163.com 
renal arteries ${ }^{2}$. Cholesterol and calcium deposits, as well as artery wall fibrosis and inflammation, can lead to lumen stenosis ${ }^{3}$. In the last two years, several guidelines have been published in an attempt to improve $\mathrm{FH}$ diagnosis and treatment ${ }^{4,5}$. Multi-contrast high-resolution magnetic resonance imaging (MRI) provides a validated and useful method to characterize carotid artery atherosclerotic plaques ${ }^{6}$. However, little is known about the usefulness of multi-contrast high-resolution MRI in HoFH patients ${ }^{7}$. We describe the use of high-resolution MRI and plaque histology in a patient with HoFH.

\section{CASE PRESENTATION}

The patient was a 28-year-old woman from Beijing, China, who presented to the Neurology Clinic with intermittent blurred vision of the right eye, headache, nausea, and vomiting for the past 8 years without obvious causes. The medical history revealed that the patient already had skin and joint xanthomas at the age of one year. HoFH was suspected at the age of 3 , when blood examination revealed plasma cholesterol $>20 \mathrm{mmol} / \mathrm{L}$, and hyperlipidemia was found in both parents. The patient's family could not afford genetic analysis or LDL-apheresis. After several years of conventional statin treatment, plasma cholesterol levels remained high, between 13 and $15 \mathrm{mmol} / \mathrm{L}$. The patient underwent percutaneous coronary intervention (PCI) at the age of 12, and coronary CT angiography showed diffuse lesions in the coronary artery with more than $50 \%$ stenosis (Fig. $1 \mathrm{~A}-\mathrm{D}$ ) as well as calcified lesions at the aortic root and coronary artery orifice (Fig. $1 \mathrm{E}$ ). We suspected that the patient's current symptoms of intermittent blurred vision might be caused by carotid artery atherosclerosis.

Therefore, carotid color Doppler ultrasound, intracranial Doppler ultrasound, and carotid artery CT angiography were performed. Carotid Doppler ultrasound showed bilateral common carotid artery (CCA), internal carotid artery (ICA), and external carotid artery (ECA) wall thickening with hyperechoic signals. The bifurcation of the right CCA showed hyperechoic plaque, with a maximum plaque thickness of $4.9 \mathrm{~mm}$; the lesion extended to the right ICA, with maximum stenosis of about $90 \%$. Right ECA stenosis was $75 \%$, while that of the left CCA, ICA, and ECA was 70\%. Transcranial Doppler ultrasound showed near occlusion of the right intracranial ICA. The right ophthalmic artery had a reverse flow, with the right ECA through the ophthalmic artery reversing ICA supply, as well as posterior communicating artery opening. Carotid artery CT angiography revealed the same degree of stenosis as the ultrasound, with plate-like calcification located at the bifurcation of the right CCA, proximal ICA, and ECA (Fig. 2 A-C).

Subsequently, high-resolution multi-contrast MRI was used to further evaluate carotid plaque components and vulnerability. Imaging was performed on a 3T MRI scanner using specially-designed phased-array
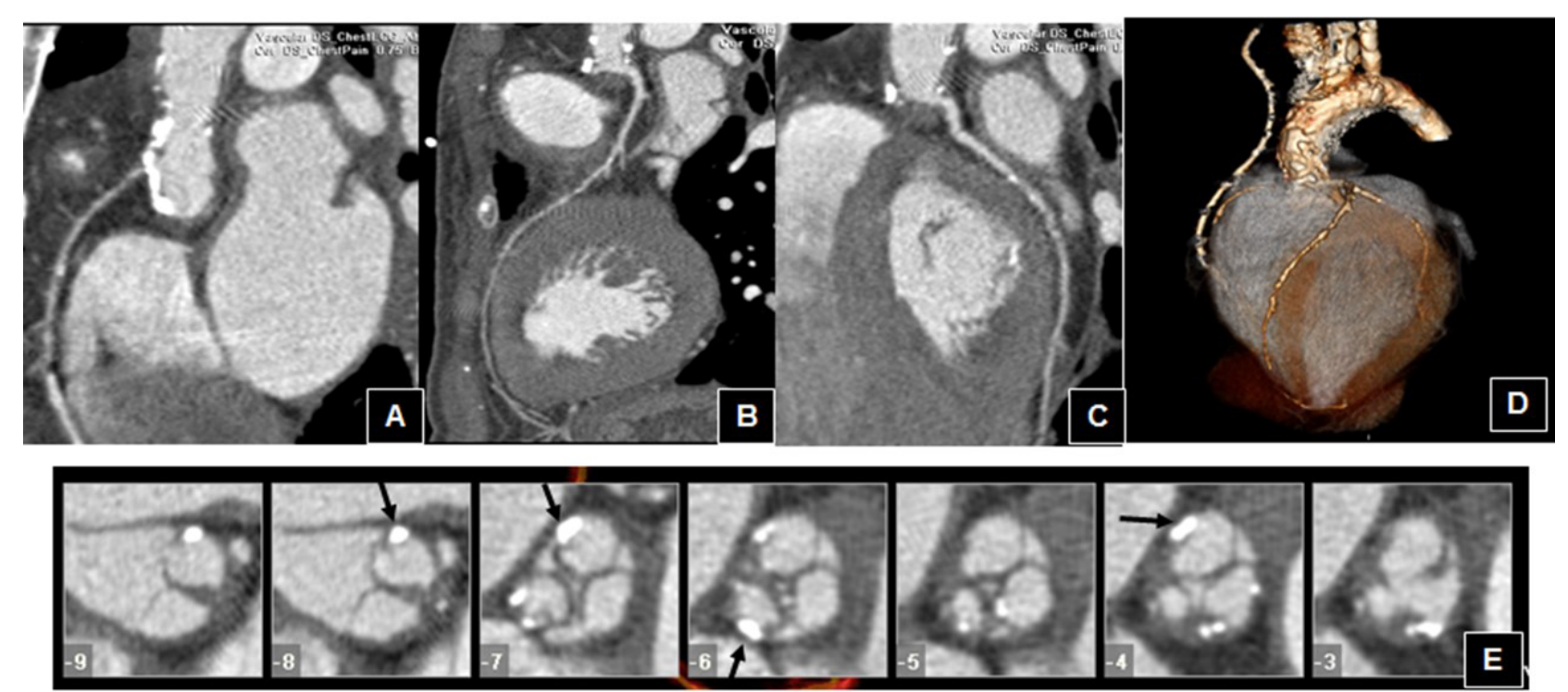

FIGURE 1. COMPUTED TOMOGRAPHY ANGIOGRAPHY OF THE PATIENT.

A-C, CALCIFIES, NON-CALCIFIED, AND MIXED PLAQUES IN THE MIDDLE AND DISTAL RCA, LAD, AND LCX; D, BYPASS FROM IMA TO RCA; E, IMAGES SHOWING CALCIFIED PLAQUES ON THE AORTIC VALVE (RED ARROWS) 


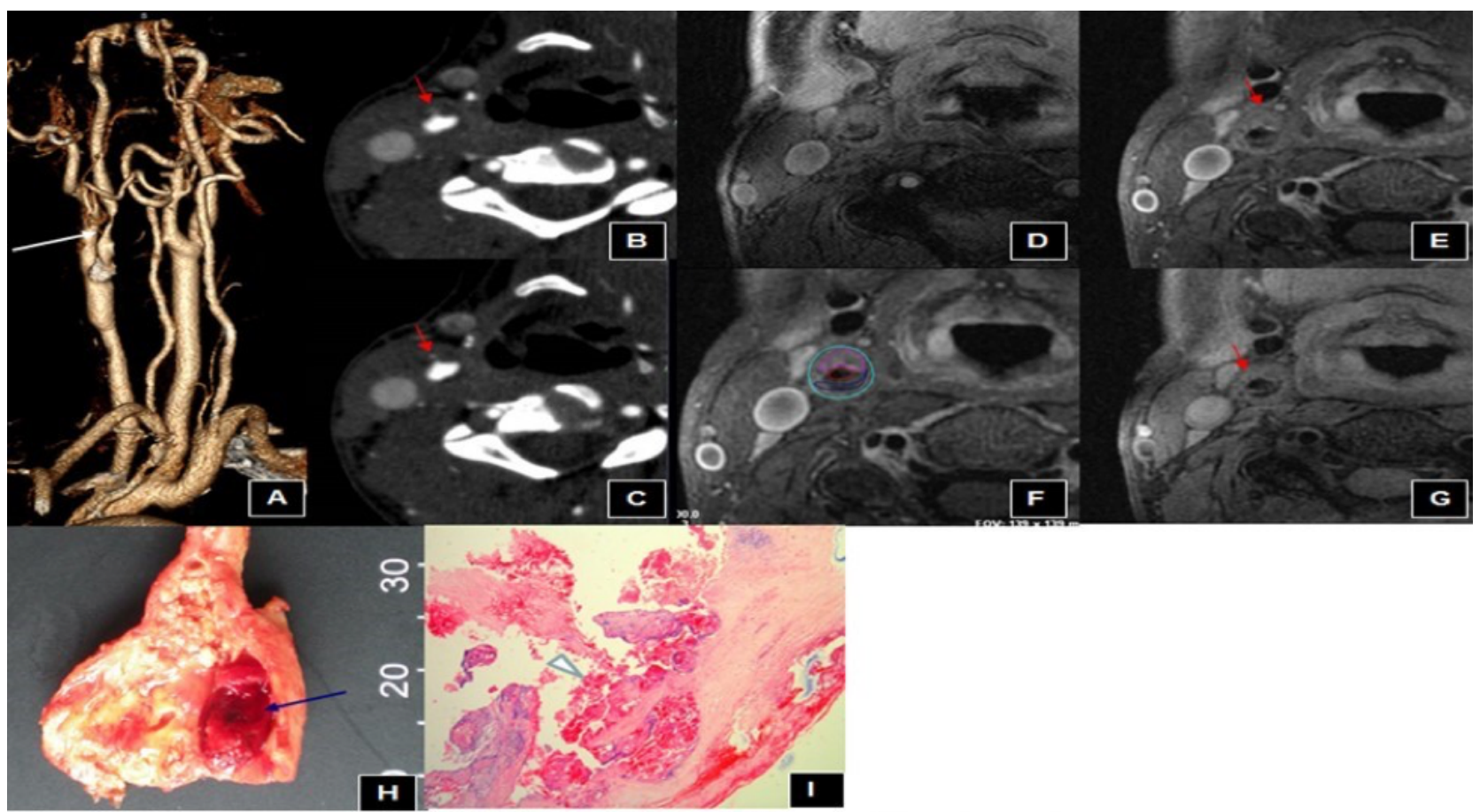

FIGURE 2. CTA, MRI, AND HISTOLOGY OF THE RIGHT CAROTID ARTERY PLAQUE.

A, CTA showed $90 \%$ stenosis in the bifurcation of the CCA and proximal ICA (white arrow); B-C, two transverse slices of the CTA showing a low-density plaque in the R-CCA (red arrow); D-G, MR, TOF, T1 W, T2W, and PD images of the R-CCA (direction and location same as in B). Red arrows indicate plaques: the pink contour shows thrombosis with an irregular surface; $\mathrm{H}$, histology showed red thrombosis on the plaque surface; I, specimen analysis confirmed the rupture, subsequent thrombus formation, and calcification (arrowhead).

\section{TABLE 1.}

\begin{tabular}{l|l} 
Time & Events \\
\hline Initial presentation & $\begin{array}{l}\text { Intermittent blurred vision of the right eye, headache, nausea, and vomiting, for the past } 8 \text { years without } \\
\text { obvious causes. }\end{array}$ \\
\hline Day 1 & $\begin{array}{l}\text { Transfer to ultrasound department for carotid color Doppler ultrasound, intracranial Doppler ultrasound, } \\
\text { which showed bilateral common carotid artery (CCA), internal carotid artery (ICA), and external carotid } \\
\text { artery (ECA) plaque with }>70 \% \text { stenosis. Right intracranial ICA was nearly occluded, with high resistance and } \\
\text { low blood flow. }\end{array}$ \\
\hline Day 2 & $\begin{array}{l}\text { Transfer to the radiology department for computed tomography carotid angiogram, which confirmed mix } \\
\text { plaque with plate-like calcification located at the bifurcation of the right CCA, proximal ICA, and ECA. lumen } \\
\text { stenosis >90\% }\end{array}$ \\
\hline Day 4 & $\begin{array}{l}\text { Transfer to the radiology department for high-resolution MRI. Carotid artery wall imaging showed plaque } \\
\text { located at the right bifurcation of the CCA extended to the ICA, lumen stenosis close to occlusion, plaque } \\
\text { surface ulcer-like with thrombosis. Lumen stenosis >90\% }\end{array}$ \\
\hline Day 15 & $\begin{array}{l}\text { Right carotid artery endarterectomy confirmed yellow fatty-like plaque with thrombosis at the bifurcation of } \\
\text { the CCA }\end{array}$ \\
\hline Outpatient clinic (6 months) & $\begin{array}{l}\text { Carotid color Doppler ultrasound showed normal blood flow of the right carotid artery and internal carotid } \\
\text { artery, without lumen stenosis. }\end{array}$ \\
\hline Marked improvement in patient's symptomatic status, no intermittent blurred vision onset
\end{tabular}

surface coils (Shanghai Chenguang Medical Technologies CO, LTD, Shanghai, China). A standardized protocol was used to obtain three different contrast-weighted images (time of flight [TOF], and T1-, T2-weighted images) of the carotid arteries $2 \mathrm{~cm}$ proximal and $2 \mathrm{~cm}$ distal to the bifurcation, respectively. MRI of the carotid showed bilateral CCA, ICA, and
ECA wall thickening, as well as diffused plaque formation. Plaque signals of the left side showed iso-intensity in TOF, T1w and T2w sequences. Calcification was reflected by hypo-intense areas located at the middle layer of the plaque, with moderate stenosis. The plaque located at the right bifurcation of the CCA extended to the ICA, causing lumen stenosis close to 
occlusion. Notably, the plaque surface was irregular, showing ulcer-like changes with slightly high signals in T1w and iso-intensity in TOF and T2w sequences (Fig. 2 D-G). Based on our clinical experience, we considered these as vulnerable plaques, which may be associated with ulcers and thrombosis.

The plaque characteristics, combined with the clinical presentation of the patient, prompted us to perform right carotid artery endarterectomy. Gross histology revealed plaque components were yellow fatty-like matter; moreover, there was thrombosis at the bifurcation of the CCA, which easily dropped from the plaque. The thrombosis was about 10mm long, with an irregular surface like ulcers (Fig. 2 H). Serial cross-sections with a thickness of $10 \mu \mathrm{m}$ or less were obtained at $0.5 \mathrm{~mm}$ intervals from each plaque specimen. These sections were stained with hematoxylin and eosin and examined microscopically by a pathologist blinded to the MRI results. Histology confirmed plaque rupture, subsequent thrombus formation, and calcification. Thus, the vulnerability of the plaque, which was suspected based on the MRI results, was confirmed through histologic examination. At 1-month follow-up, carotid color Doppler ultrasound showed normal flow and no lumen stenosis of the right carotid artery and internal carotid artery blood. At six months follow-up, the patient did not report a recurrence of her symptoms.

\section{DISCUSSION}

Patients with FH are at very high risk of developing atherosclerosis at a young age. Increased carotid intima-media thickness (IMT) and carotid plaques may be apparent in FH patients already during childhood and (especially in $\mathrm{HoFH}$ ) may lead to clinical events before reaching adulthood, as in the patient described in our case report. Carotid plaque burden may be assessed by carotid ultrasonography ${ }^{8}$. More detailed characterization of plaques in $\mathrm{HoFH}$ patients may be useful for risk stratification and as an outcome measure in clinical studies. However, very few studies have been done on assessing plaque composition in patients with $\mathrm{FH}$, especially in $\mathrm{HoFH}^{9}$. High-resolution MRI of the carotid artery has the ability to qualitatively and quantitatively assess the main components of advanced human carotid atherosclerotic plaques in vivo and was found to correlate with findings of histologic plaques ${ }^{10}$. MRI-based quantification is accurate and reproducible and has, therefore, been used as an endpoint in clinical studies of anti-atherosclerotic therapies. However, previous studies were mainly focused on the plaque burden in the aorta wall in asymptomatic patients with heterozygous FH by using MRI ${ }^{11-13}$. Therefore, our data on carotid plaque burden may provide some information to the patients with HoFH.

\section{CONCLUSION}

Our case demonstrates that high-resolution multi-contrast MRI played an excellent role in identifying carotid plaque components in a patient with $\mathrm{HoFH}$, which can help clinical physicians reach a diagnosis and provide an intervention earlier so as to minimize the risk of developing atherosclerotic cardiovascular disease and related complications.

\section{List of abbreviations}

HoFH = Homozygous familial hypercholesterolemia ACVD = atherosclerotic cardiovascular disease PCI = percutaneous coronary intervention CCA = bilateral common carotid artery

ICA = internal carotid artery

$\mathrm{ECA}=$ external carotid artery

$\mathrm{MR}=$ magnetic resonance

TOF = time of flight

$\mathrm{T} 1 \mathrm{w}=\mathrm{T} 1$-weighted

$\mathrm{T} 2 \mathrm{w}=\mathrm{T} 2$ weighted

IMT $=$ intima-media thickness

\section{Declarations}

Ethical Approval and Consent to participate

The study has been approved by the Beijing AnZhen Hospital ethics review board. The design is reasonable, data collection standardized, and the relevant rights and interests of the patients have been fully protected.

\section{Consent for publication}

Not applicable.

\section{Availability of data and materials}

The datasets used and/or analyzed during the current study are available from the corresponding author on reasonable request.

\section{Funding}

This work was supported by grants from the Natural Science Foundation of Beijing (17L20194).

\section{Acknowledgments}

We thank the Beijing Institute of Heart, Lung, and 
Blood Vessel Diseases for providing experimental technology support. We especially thank the patient and her family for generously consenting to the publication of this case report.

\section{Competing interests \\ There are no conflicts of interest.}

\section{Authors' contribution}

Conception and design: Zhenjia Wang and Wei Yu. Collection and assembly of data: Zhenjia Wang and Wen Liu. Data analysis and interpretation: Zhenjia Wang, Long Jiang, and Luya Wang. Manuscript writing: Zhenjia Wang and Wei Yu. Revised the language/ article and final approval of manuscript: all authors.

\section{RESUMO}

A hipercolesterolemia familiar homozigótica, uma doença patogênica rara do metabolismo da lipoproteína intimamente relacionada com a doença cardiovascular aterosclerótica prematura, pode conduzir a uma elevada deficiência e mortalidade. A hipercolesterolemia familiar homozigótica afeta tipicamente não só a raiz aórtica, comprometendo os óstios coronários, mas também outros territórios, como a carótida, a aorta descendente e as artérias renais. Imagens de ressonância magnética multicontraste de alta resolução (RM) fornecem um método validado e útil para caracterizar quantitativamente as placas de aterosclerose da artéria carótida. No entanto, muito poucos estudos foram feitos sobre a avaliação da composição da placa em doentes com hipercolesterolemia familiar homozigótica utilizando ressonância magnética de alta resolução. Este trabalho deve avaliar o valor da ressonância magnética no acesso à doença da artéria carótida em doentes com hipercolesterolemia familiar homozigótica. Descrevemos um paciente de 28 anos de Pequim, China, que se apresentou à clínica neurológica com visão turva intermitente do olho direito, dor de cabeça, náuseas e vômitos por oito anos sem causas aparentes. Suspeitava-se de hipercolesterolemia familiar com base no histórico médico e no exame laboratorial. O ultrassom Doppler carotídeo mostrou uma artéria carótida bilateral comum, artéria carótida interna e parede da carótida externa espessando-se com sinais hiperecoicos. Posteriormente, a ressonância multicontraste de alta resolução da carótida mostrou calcificação com áreas hipointensas localizadas na camada média da placa, com estenose moderada. A placa localizada na bifurcação direita da artéria carótida comum estendia-se até a artéria carótida interna, causando estenose do lúmen próxima à oclusão. O paciente foi tratado com endarterectomia da artéria carótida direita. Em seis meses de acompanhamento, não houve recorrência dos sintomas do paciente.

PALAVRAS-CHAVE: Espectroscopia de ressonância magnética. Placa aterosclerótica. Espessura íntima-média da carótida. Artérias carótidas. Hiperlipoproteinemia tipo II.

\section{REFERENCES}

1. Cuchel M, Bruckert E, Ginsberg HN, Raal FJ, Santos RD, Hegele RA, et al; European Atherosclerosis Society Consensus Panel on Familial Hypercholesterolaemia. Homozygous familial hypercholesterolaemia: new insights and guidance for clinicians to improve detection and clinical management. A position paper from the Consensus Panel on Familial Hypercholesterolaemia of the European Atherosclerosis Society. Eur Heart J. 2014;35(32):2146-57.

2. Kolansky DM, Cuchel M, Clark BJ, Paridon S, McCrindle BW, Wiegers SE, et al. Longitudinal evaluation and assessment of cardiovascular disease in patients with homozygous familial hypercholesterolemia. Am J Cardiol. 2008;102(11):1438-43.

3. Nordestgaard BG, Chapman MJ, Humphries SE, Ginsberg HN, Masana L, Descamps OS, et al; European Atherosclerosis Society Consensus Panel. Familial hypercholesterolaemia is underdiagnosed and undertreated in the general population: guidance for clinicians to prevent coronary heart disease: consensus statement of the European Atherosclerosis Society. Eur Heart J. 2013;34(45):3478-90a.

4. Watts GF, Gidding S, Wierzbicki AS, Toth PP, Alonso R, Brown WV, et al: International FH Foundation. Integrated guidance on the care of familial hypercholesterolaemia from the International FH Foundation: executive summary. J Atheroscler Thromb. 2014;21(4):368-74.

5. Gidding SS, Champagne MA, Ferranti SD, Defesche J, Ito MK, Knowles JW, et al; American Heart Association Atherosclerosis, Hypertension, and Obesity in Young Committee of Council on Cardiovascular Disease in Young, Council on Cardiovascular and Stroke Nursing, Council on Functional Genomics and Translational Biology, and Council on Lifestyle and Cardiometabolic Health. The agenda for familial hypercholesterolemia: a scientific statement from the American Heart Association. Circulation. 2015;132(22):2167-92.

6. Narumi S, Sasaki M, Ohba H, Ogasawara K, Kobayashi M, Hitomi J, et al.
Prediction of carotid plaque characteristics using non-gated MR imaging: correlation with endarterectomy specimens. AJNR Am J Neuroradiol. 2013;34(1):191-7.

7. Summers RM, Andrasko-Bourgeois J, Feuerstein IM, Hill SC, Jones EC, Busse $M K$, et al. Evaluation of the aortic root by MRI: insights from patients with homozygous familial hypercholesterolemia. Circulation. 1998;98(6):509-18.

8. ten Kate GL, ten Kate G), van den Oord SC, Dedic A, Dharampal AS, Nieman $\mathrm{K}$, et al. Carotid plaque burden as a measure of subclinical coronary artery disease in patients with heterozygous familial hypercholesterolemia. Am J Cardiol. 2013;111(9):1305-10.

9. Saam T, Ferguson MS, Yarnykh VL, Takaya N, Xu D, Polissar NL, et al. Quantitative evaluation of carotid plaque composition by in vivo MRI. Arterioscler Thromb Vasc Biol. 2005;25(1):234-9.

10. Pletsch-Borba L, Selwaness M, van der Lugt A, Hofman A, Franco OH, Vernooij MW. Change in carotid plaque components: a 4-year follow-up study with serial MR imaging. JACC Cardiovasc Imaging. 2018;11(2 Pt 1):184-92.

11. Caballero $P$, Alonso R, Rosado $P$, Mata N, Fernández-Friera L, Jiménez-Borreguero $L$ J, et al. Detection of subclinical atherosclerosis in familial hypercholesterolemia using non-invasive imaging modalities. Atherosclerosis. 2012;222(2):468-72.

12. Soljanlahti S, Autti T, Hyttinen L, Vuorio AF, Keto P, Lauerma K. Compliance of the aorta in two diseases affecting vascular elasticity, familial hypercholesterolemia and diabetes: a MRI study. Vasc Health Risk Manag. 2008;4(5):1103-9.

13. Schmitz SA, O'Regan DP, Fitzpatrick J, Neuwirth C, Potter E, Tosi I, et al. Quantitative 3T MR imaging of the descending thoracic aorta: patients with familial hypercholesterolemia have an increased aortic plaque burden despite long-term lipid-lowering therapy. J Vasc Interv Radiol. 2008;19(10):1403-8. 